\title{
Involvement of SAPK/JNK in basic fibroblast growth factor-induced vascular endothelial growth factor release in osteoblasts
}

\author{
H Tokuda ${ }^{1,2}$, K Hirade ${ }^{2}$, X Wang ${ }^{2}$, Y Oiso ${ }^{3}$ and O Kozawa ${ }^{2}$ \\ ${ }^{1}$ Department of Internal Medicine, Chubu National Hospital - National Institute for Longevity Sciences, Obu, Aichi 474-8511, Japan \\ ${ }^{2}$ Department of Pharmacology, Gifu University School of Medicine, Gifu 500-8705, Japan \\ ${ }^{3}$ First Department of Internal Medicine, Nagoya University School of Medicine, Nagoya 466-8550, Japan \\ (Requests for offprints should be addressed to O Kozawa; Email: okozawa@cc.gifu-u.ac.jp)
}

\begin{abstract}
We previously reported that basic fibroblast growth factor (FGF-2) activates $\mathrm{p} 44 / \mathrm{p} 42$ mitogen-activated protein (MAP) kinase resulting in the stimulation of vascular endothelial growth factor (VEGF) release in osteoblast-like MC3T3-E1 cells and that FGF-2-activated p38 MAP kinase negatively regulates VEGF release. In the present study, we investigated the involvement of stress-activated protein kinase/c-Jun $\mathrm{N}$-terminal kinase (SAPK/JNK) in FGF-2-induced VEGF release in these cells. FGF-2 markedly induced the phosphorylation of SAPK/JNK. SP600125, an inhibitor of SAPK/JNK, markedly reduced the FGF-2-induced VEGF release. SP600125 suppressed
\end{abstract}

the FGF-2-induced phosphorylation of SAPK/JNK without affecting the phosphorylation of $\mathrm{p} 44 / \mathrm{p} 42$ MAP kinase or p38 MAP kinase induced by FGF-2. PD98059, an inhibitor of upstream kinase of p44/p42 MAP kinase, or SB203580, an inhibitor of $\mathrm{p} 38$ MAP kinase, failed to affect the FGF-2-induced phosphorylation of SAPK/JNK. A combination of SP600125 and SB203580 suppressed the FGF-2-stimulated VEGF release in an additive manner. These results strongly suggest that FGF-2 activates SAPK/ JNK in osteoblasts, and that SAPK/JNK plays a part in FGF-2-induced VEGF release.

Journal of Endocrinology (2003) 177, 101-107

\section{Introduction}

Vascular endothelial growth factor (VEGF) has been characterized as a heparin-binding angiogenic growth factor displaying high specificity for vascular endothelial cells (Ferrara \& Davis-Smyth 1997). It is well recognized that VEGF, which is produced and secreted from a variety of cell types, increases capillary permeability and stimulates proliferation of endothelial cells (Ferrara \& Davis-Smyth 1997). As for bone metabolism, it has been shown that inactivation of VEGF causes complete suppression of blood vessel invasion concomitant with impaired trabecular bone formation and expansion of the hypertropic chondrocyte zone in mouse tibial epiphyseal growth plate (Gerber et al. 1999). Accumulating evidence indicates that osteoblasts among bone cells produce and secrete VEGF in response to various humoral factors (Goad et al. 1996, Wang et al. 1996, Ferrara \& Davis-Smyth 1997, Schalaeppi et al. 1997). Bone metabolism is regulated by two functional cells, osteoblasts and osteoclasts, the former responsible for bone formation and the latter for bone resorption (Nijweide et al. 1986). During bone remodeling, capillary endothelial cells provide the microvasculature, and osteoblasts and osteoprogenitor cells, which locally proliferate and differentiate into osteoblasts, migrate into the resorption lacuna. It is currently recognized that the activities of osteoblasts, osteoclasts and capillary endothelial cells are closely coordinated via humoral factors as well as by direct cell-to-cell contact, and these cells cooperatively regulate bone metabolism (Erlebacher et al. 1995). Thus, there is no doubt that VEGF secreted from osteoblasts plays an important role in the regulation of bone metabolism. However, the mechanism behind VEGF synthesis in osteoblasts has not yet been fully clarified.

Basic fibroblast growth factor (FGF-2) is found in bone matrix, and osteoblasts synthesize FGF-2 (Baylink et al. 1993, Hurley et al. 1993). FGF-2 expression in osteoblasts is detected during fracture repair (Bolander 1992). Thus, it is recognized that FGF-2 plays a crucial role in fracture healing and bone remodeling. There are four structurally related high affinity receptors (FGF receptors $1-4$ ) that possess an intrinsic protein tyrosine kinase activity and induce tyrosine autophosphorylation of the receptors (Johnson \& Williams 1993). We have shown that FGF receptors 1 and 2 are autophosphorylated by FGF-2 in osteoblast-like MC3T3-E1 cells (Suzuki et al. 1996). In addition, we have reported that FGF-2 stimulates VEGF release in MC3T3-E1 cells, and that p44/p42 mitogenactivated protein (MAP) kinase participates, at least partly, in VEGF release while p38 MAP kinase limits VEGF 
A Phospho-SAPK/JNK

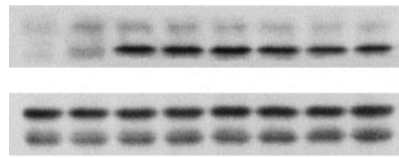

SAPK/JNK

$\begin{array}{llllllll}1 & 2 & 3 & 4 & 5 & 6 & 7 & 8\end{array}$

Time (min)

$0 \begin{array}{lllll}0 & 3 & 5 & 10203060\end{array}$

FGF-2 -++++++

\section{B Phospho-SAPK/JNK}

SAPK/JNK

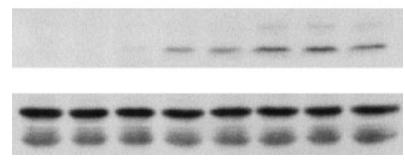

Lane

$\begin{array}{llllllll}1 & 2 & 3 & 4 & 5 & 6 & 7 & 8\end{array}$

Time (min)

013510203060

FGF-2

Figure 1 Effect of FGF-2 on the phosphorylation of SAPK/JNK in MC3T3-E1 cells. The cultured cells were stimulated with $30 \mathrm{ng} / \mathrm{ml}$ FGF-2 (A) or $2 \mathrm{ng} / \mathrm{ml} \mathrm{FGF-2} \mathrm{(B)} \mathrm{for} \mathrm{the} \mathrm{indicated} \mathrm{periods.} \mathrm{The}$ extracts of cells were subjected to SDS-PAGE with subsequent Western blotting analysis with antibodies against phospho-specific SAPK/JNK (phospho-SAPK/JNK) or SAPK/JNK. The upper and lower bands indicate p54 and p46 SAPK/JNK respectively. Lane 1, control cells.

release (Tokuda et al. 2000). It has recently been reported that stress-activated protein kinase/c-Jun N-terminal kinase (SAPK/JNK), which belongs to the MAP kinase superfamily (Widmann et al. 1999), is activated by FGF-2 in mouse myocytes and breast cancer cells (Liu et al. 1999, Sheikh et al. 2001), leading us to speculate involvement of SAPK/JNK in FGF-2-induced VEGF release in osteoblasts. However, the involvement of JNK in FGF-2 signaling in osteoblasts has not yet been clarified.

In the present study, we investigated the involvement of SAPK/JNK in the FGF-2-induced VEGF release in osteoblast-like MC3T3-E1 cells. Here we show that FGF-2 activates SAPK/JNK in addition to $\mathrm{p} 44 / \mathrm{p} 42$ MAP kinase and p38 MAP kinase in these cells, and that SAPK/JNK plays a role as a positive regulator in FGF-2induced VEGF release.

\section{Materials and Methods}

\section{Materials}

FGF-2 and mouse VEGF enzyme immunoassay kits were purchased from R\&D Systems, Inc. (Minneapolis, MN, USA). SP600125, SB203580 and PD98059 were obtained from Calbiochem Novabiochem Co. (La Jolla, CA, USA). Phospho-specific SAPK/JNK antibodies, SAPK/JNK antibodies, phospho-specific p44/p42 MAP kinase antibodies, p44/p42 MAP kinase antibodies, phospho-specific

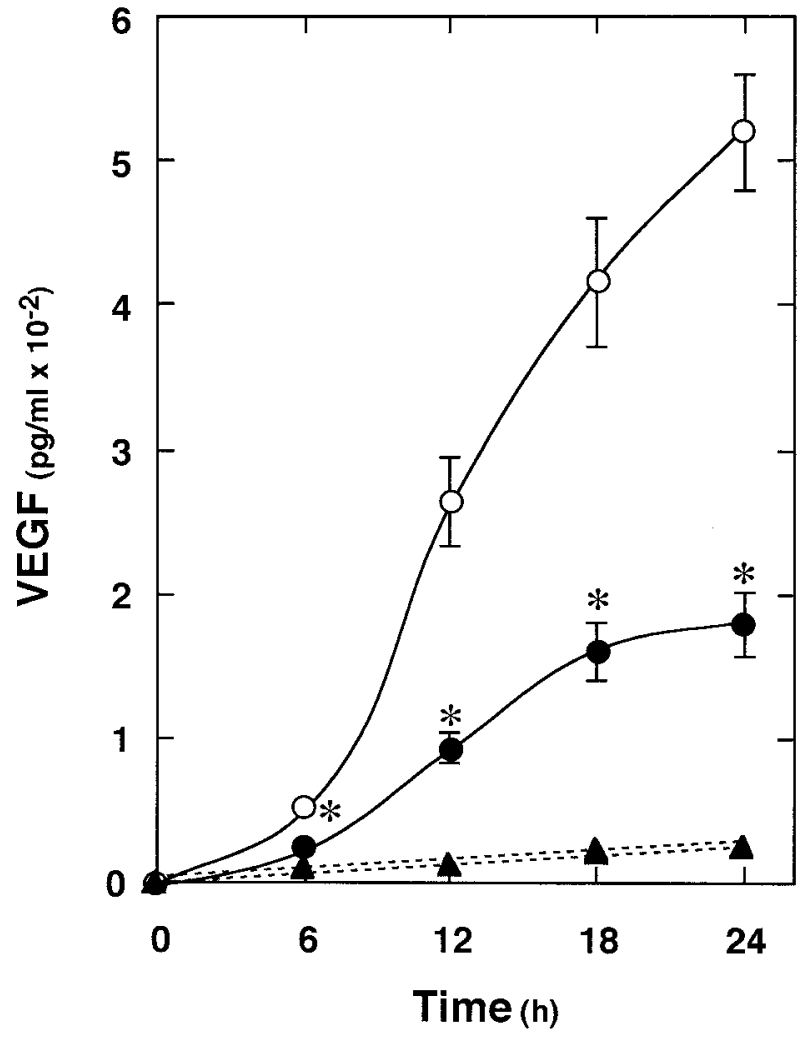

Figure 2 Effect of SP600125 on the FGF-2-induced VEGF release in MC3T3-E1 cells. The cultured cells were pretreated with $10 \mu \mathrm{M}$ SP600125 (closed symbols) or vehicle (open symbols) for $60 \mathrm{~min}$, and then stimulated with $30 \mathrm{ng} / \mathrm{ml} \mathrm{FGF-2} \mathrm{(circles)} \mathrm{or} \mathrm{vehicle}$ (triangles) for the indicated periods. Each value represents the mean \pm S.E.M. of triplicate determinations. Similar results were obtained with two additional and different cell preparations. ${ }^{*} P<0.05$ compared with the value of FGF-2 alone.

p38 MAP kinase antibodies and p38 MAP kinase antibodies were purchased from New England BioLabs, Inc. (Beverly, MA, USA). ECL Western blotting detection system was purchased from Amersham Japan (Tokyo, Japan). Other materials and chemicals were obtained from commercial sources. SP600125, SB203580 or PD98059 were dissolved in dimethyl sulfoxide (DMSO). The maximum concentration of DMSO was $0 \cdot 1 \%$, which did not affect the assay for VEGF or the analysis of MAP kinases.

\section{Cell culture}

Cloned osteoblast-like MC3T3-E1 cells derived from newborn mouse calvaria (Sudo et al. 1983) were maintained as previously described (Kozawa et al. 1992). Briefly, the cells were cultured in $\alpha$-minimum essential medium ( $\alpha$-MEM) containing 10\% fetal calf serum (FCS) at $37{ }^{\circ} \mathrm{C}$ in a humidified atmosphere of $5 \% \mathrm{CO}_{2} / 95 \%$ air. The cells were seeded into $35-\mathrm{mm}$ diameter dishes or 90-mm diameter dishes in $\alpha$-MEM containing 10\% FCS. 


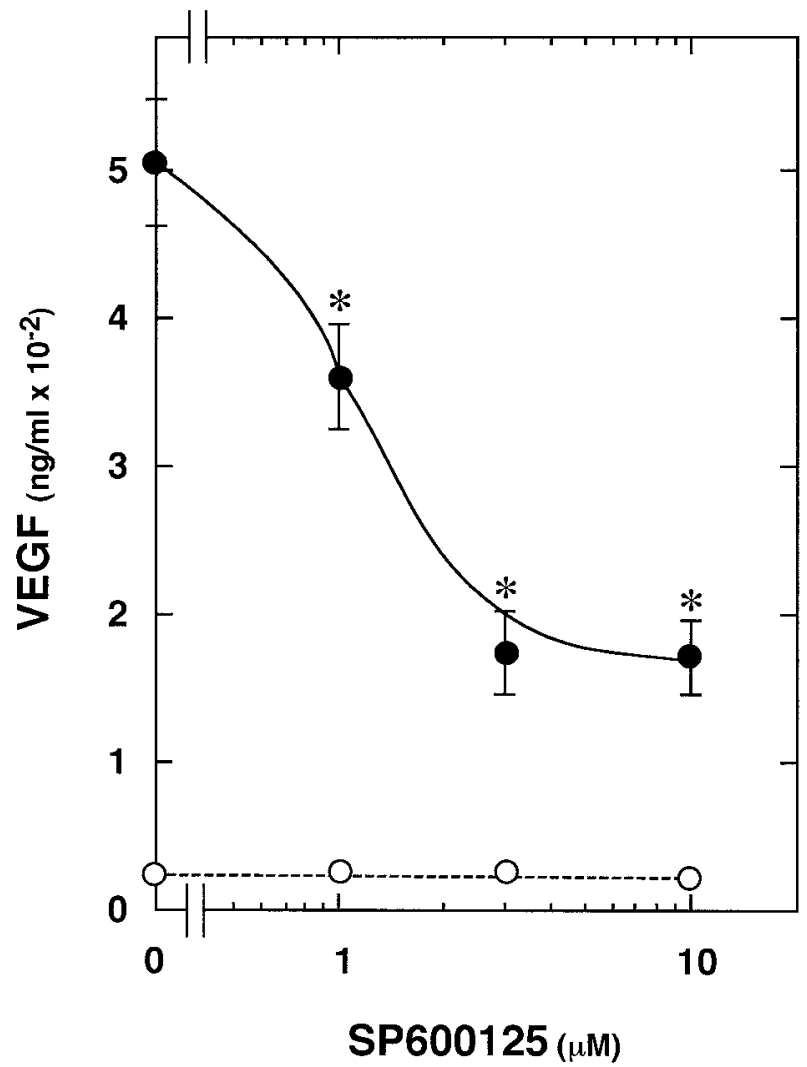

Figure 3 Dose-dependent effect of SP600125 on the FGF-2induced VEGF release in MC3T3-E1 cells. The cultured cells were pretreated with various doses of SP600125 for $60 \mathrm{~min}$, and then stimulated with $30 \mathrm{ng} / \mathrm{ml} \mathrm{FGF-2} \mathrm{(solid} \mathrm{circles)} \mathrm{or} \mathrm{vehicle} \mathrm{(open}$ circles) for $24 \mathrm{~h}$. Each value represents the mean \pm S.E.M. of triplicate determinations. Similar results were obtained with two additional and different cell preparations. ${ }^{*} P<0.05$ compared with the value of FGF-2 alone.

After 5 days, the medium was exchanged for $\alpha$-MEM containing $0 \cdot 3 \%$ FCS. The cells were used for experiments after $48 \mathrm{~h}$.

\section{VEGF assay}

The cultured cells were stimulated with FGF-2 in $1 \mathrm{ml}$ $\alpha$-MEM containing $0 \cdot 3 \%$ FCS for the indicated periods. When indicated, the cells were pretreated with SB203580 or SP600125 for $60 \mathrm{~min}$. The reaction was terminated by collecting the medium, and VEGF in the medium was measured by a VEGF enzyme immunoassay kit.

\section{Analysis of MAP kinases}

The cultured cells were stimulated by FGF- 2 in $\alpha$-MEM containing $0 \cdot 3 \%$ FCS for the indicated periods. The cells were washed twice with phosphate-buffered saline and then lysed, homogenized and sonicated in a lysis buffer

\section{Phospho-SAPK/JNK}

$$
\text { SAPK/JNK }
$$
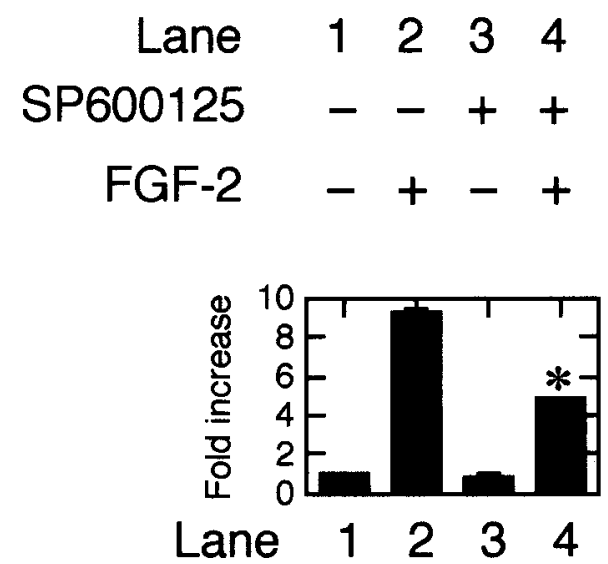

Figure 4 Effect of SP600125 on the FGF-2-induced phosphorylation of SAPK/JNK in MC3T3-E1 cells. The cultured cells were pretreated with $10 \mu \mathrm{M} \mathrm{SP} 600125$ or vehicle for $60 \mathrm{~min}$, and then stimulated with $30 \mathrm{ng} / \mathrm{ml} \mathrm{FGF-2} \mathrm{or} \mathrm{vehicle} \mathrm{for} 20 \mathrm{~min}$. The extracts of cells were subjected to SDS-PAGE with subsequent Western blotting analysis with antibodies against phospho-specific SAPK/JNK (phospho-SAPK/JNK) or SAPK/JNK. The histogram shows quantitative representations of the levels of FGF-2-induced phosphorylation obtained from laser densitometric analysis of three independent experiments. Each value represents the mean \pm S.E.M. of triplicate determinations. Similar results were obtained with two additional and different cell preparations. ${ }^{*} P<0 \cdot 05$ compared with the value of FGF-2 alone.

containing $62.5 \mathrm{mM}$ Tris/ $\mathrm{HCl}, \mathrm{pH} \quad 6 \cdot 8,2 \%$ sodium dodecyl sulfate (SDS), $50 \mathrm{mM}$ dithiothreitol and $10 \%$ glycerol. The cytosolic fraction was collected as a supernatant after centrifugation at $125000 \times \mathbf{g}$ for $10 \mathrm{~min}$ at $4{ }^{\circ} \mathrm{C}$. SDS-polyacrylamide gel electrophoresis (PAGE) was performed by the method of Laemmli (1970) in a $10 \%$ polyacrylamide gel. Western blotting analysis was performed as described previously (Kato et al. 1996) by using phospho-specific SAPK/JNK antibodies, SAPK/JNK antibodies, phospho-specific p38 MAP kinase antibodies or p38 MAP kinase antibodies, with peroxidase-labeled antibodies raised in goat against rabbit $\operatorname{IgG}$ being used as second antibodies. Peroxidase activity on the nitrocellulose sheet was visualized on X-ray film by means of the ECL Western blotting detection system. When indicated, the cells were pretreated with SP600125 or SB203580 for $60 \mathrm{~min}$.

\section{Determination}

The absorbance of enzyme immunoassay samples was measured at $450 \mathrm{~nm}$ with an EL 340 Bio Kinetic Reader 
Phospho-p44/p42

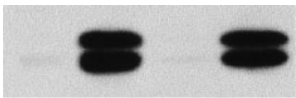

p44/p42
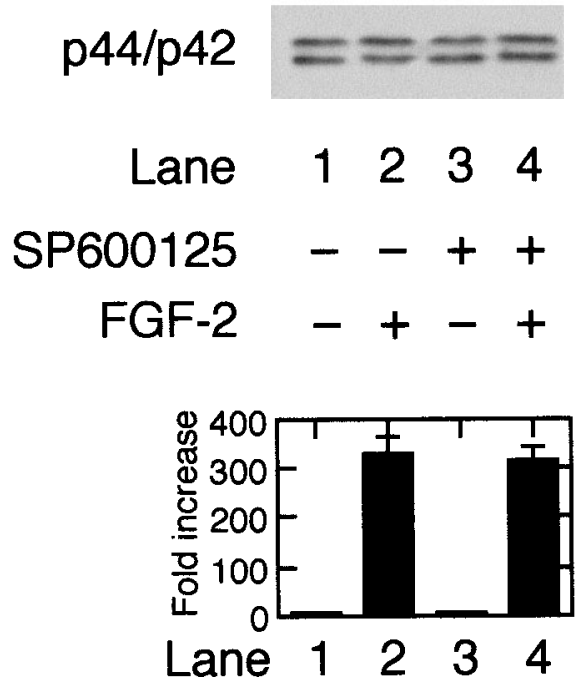

Figure 5 Effect of SP600125 on the FGF-2-induced phosphorylation of p44/p42 MAP kinase in MC3T3-E1 cells. The cultured cells were pretreated with $10 \mu \mathrm{M}$ SP600125 or vehicle for $60 \mathrm{~min}$, and then stimulated with $30 \mathrm{ng} / \mathrm{ml} \mathrm{FGF-2} \mathrm{or} \mathrm{vehicle} \mathrm{for}$ $20 \mathrm{~min}$. The extracts of cells were subjected to SDS-PAGE with subsequent Western blotting analysis with antibodies against phospho-specific p44/p42 MAP kinase (phospho-p44/p42) or $\mathrm{p} 44 / \mathrm{p} 42$ MAP kinase (p44/p42). The histogram shows quantitative representations of the levels of FGF-2-induced phosphorylation obtained from laser densitometric analysis of three independent experiments. Each value represents the mean \pm S.E.M. of triplicate determinations. Similar results were obtained with two additional and different cell preparations.

(Bio-Tek Instruments, Inc., Winooski, VT, USA). The densitometric analysis was performed using Molecular Analyst/Macintosh (Bio-Rad Laboratories, Hercules, CA, USA).

\section{Statistical analysis}

The data were analyzed by ANOVA followed by the Bonferroni method for multiple comparisons between pairs, and a value of $P<0 \cdot 05$ was considered significant. All data are presented as the mean \pm S.E.M. of triplicate determinations. Each experiment was repeated three times with similar results.

\section{Results}

Effect of FGF-2 on the phosphorylation of SAPK/JNK in MC3T3-E1 cells

To clarify whether FGF-2 activates SAPK/JNK in osteoblast-like MC3T3-E1 cells, we examined the effect

\section{Phospho-p38}

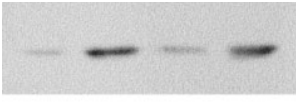

p38
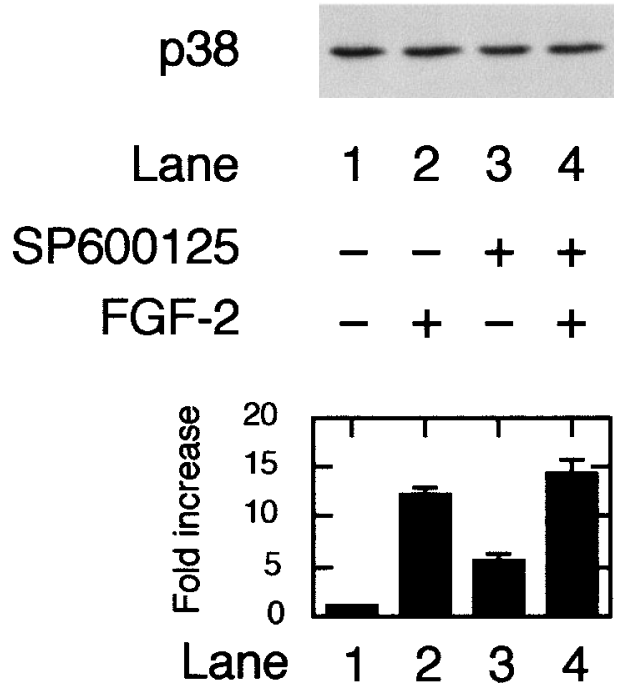

Figure 6 Effect of SP600125 on the FGF-2-induced phosphorylation of p38 MAP kinase in MC3T3-E1 cells. The cultured cells were pretreated with $10 \mu \mathrm{M}$ SP600125 or vehicle for $60 \mathrm{~min}$, and then stimulated with $30 \mathrm{ng} / \mathrm{ml} \mathrm{FGF-2} \mathrm{or} \mathrm{vehicle} \mathrm{for}$ $10 \mathrm{~min}$. The extracts of cells were subjected to SDS-PAGE with subsequent Western blotting analysis with antibodies against phospho-specific p38 MAP kinase (phospho-p38) or p38 MAP kinase (p38). The histogram shows quantitative representations of the levels of FGF-2-induced phosphorylation obtained from laser densitometric analysis of three independent experiments. Each value represents the mean \pm S.E.M. of triplicate determinations. Similar results were obtained with two additional and different cell preparations.

of FGF-2 on the SAPK/JNK phosphorylation. FGF-2 (30 $\mathrm{ng} / \mathrm{ml}$ ) markedly induced phosphorylation of SAPK/ JNK in a time-dependent manner up to $60 \mathrm{~min}$ (Fig. 1A). The FGF-2-induced phosphorylation of SAPK/JNK was also observed with $2 \mathrm{ng} / \mathrm{ml}$, a more physiological concentration of FGF-2 (Esch et al. 1985) (Fig. 1B).

Effect of SP600125 on the FGF-2-induced VEGF release in MC3T3-E1 cells

We have previously shown that FGF-2 stimulates VEGF release in osteoblast-like MC3T3-E1 cells (Tokuda et al. 2000). To investigate whether SAPK/JNK is involved in the FGF-2-induced VEGF release in MC3T3-E1 cells, we examined the effect of SP600125, a highly specific inhibitor of JNK, on the release (Bennett et al. 2001). SP600125, which alone hardly affected the basal level of VEGF, significantly reduced the FGF-2-induced VEGF release (Fig. 2). The inhibitory effect of SP600125 on the FGF-2-induced VEGF release was dose-dependent in the range between 1 and $10 \mu \mathrm{M}$ (Fig. 3). The maximum 


\section{Phospho-SAPK/JNK}

SAPK/JNK

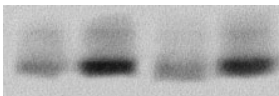

Phospho-SAPK/JNK

SAPK/JNK
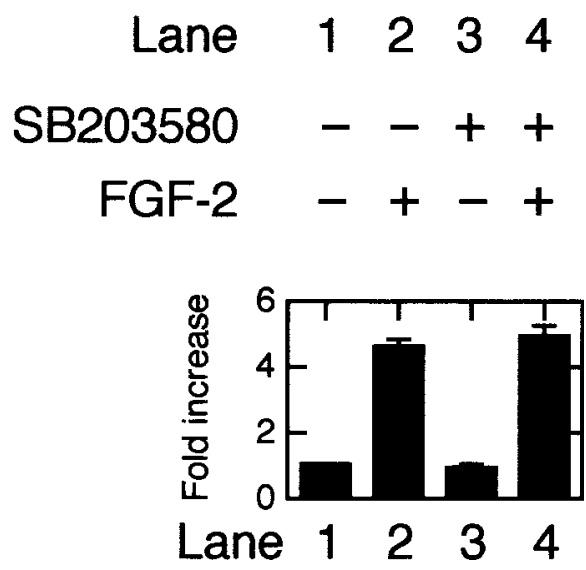

Figure 7 Effect of PD98059 on the FGF-2-induced phosphorylation of SAPK/JNK in MC3T3-E1 cells. The cultured cells were pretreated with $50 \mu \mathrm{M}$ PD98059 or vehicle for $60 \mathrm{~min}$, and then stimulated with $30 \mathrm{ng} / \mathrm{ml} \mathrm{FGF-2} \mathrm{or} \mathrm{vehicle} \mathrm{for} 20 \mathrm{~min}$. The extracts of cells were subjected to SDS-PAGE with subsequent Western blotting analysis with antibodies against phospho-specific SAPK/JNK (phospho-SAPK/JNK) or SAPK/JNK. The histogram shows quantitative representations of the levels of FGF-2-induced phosphorylation obtained from laser densitometric analysis of three independent experiments. Each value represents the mean \pm S.E.M. of triplicate determinations. Similar results were obtained with two additional and different cell preparations.

inhibitory effect of SP600125 was observed at $10 \mu \mathrm{M}$, which caused about 70\% reduction in the FGF-2 effect.

Effects of SP600125 on the phosphorylation of SAPK/JNK, p44/p42 MAP kinase and p38 MAP kinase induced by FGF-2 in MC3T3-E1 cells

We found that SP600125 truly inhibited the phosphorylation of SAPK/JNK induced by FGF-2 (Fig. 4). According to the densitometric analysis, SP600125 caused about $50 \%$ reduction of the FGF-2 effect on the SAPK/ JNK phosphorylation. On the other hand, SP600125 had little effect on the FGF-2-induced phosphorylation of p44/p42 MAP kinase (Fig. 5). In addition, p38 MAP kinase was not affected by SP600125 (Fig. 6).

Effect of PD98059 or SB203580 on the FGF-2-induced phosphorylation of SAPK/JNK in MC3T3-E1 cells

PD98059, an inhibitor of the upstream kinase that activates $\mathrm{p} 44 / \mathrm{p} 42$ MAP kinase (Alessi et al. 1995), failed to affect the FGF-2-induced phosphorylation of SAPK/JNK (Fig. 7). Additionally, SB203580, an inhibitor of p38 MAP kinase (Cuenda et al. 1995), had little effect on the FGF-2-induced phosphorylation of SAPK/JNK (Fig. 8).

Effect of a combination of SP600125 and PD98059 on the FGF-2-stimulated VEGF release in MC3T3-E1 cells

We further examined the effect of a combination of SP600125 and PD98059 on the FGF-2-stimulated VEGF release in these cells. A combination of SP600125 and PD98059 significantly reduced the FGF-2-stimulated VEGF release in an additive manner (Table 1).

\section{Discussion}

It is currently known that the MAP kinase superfamily mediates intracellular signaling of extracellular agonists and plays a crucial role in cellular functions including proliferation, differentiation, and cell death in a variety of cells (Widmann et al. 1999). Three major MAP kinases, p44/ p42 MAP kinase, p38 MAP kinase, and SAPK/JNK are known as central elements used by mammalian cells to 
Table 1 Effect of a combination of SP600125 and SB203580 on the FGF-2-stimulated VEGF release in MC3T3-E1 cells. The cultured cells were pretreated with $1 \mu \mathrm{M}$ SP600125, $10 \mu \mathrm{M}$ PD98059 or vehicle for $60 \mathrm{~min}$, and then stimulated with $30 \mathrm{ng} / \mathrm{ml} \mathrm{FGF-2}$ or vehicle for $48 \mathrm{~h}$. Each value represents the mean \pm S.E.M. of triplicate determinations. Similar results were obtained with two additional and different cell preparations

\begin{tabular}{lllc} 
& & & VEGF $(\mathrm{pg} / \mathrm{ml})$ \\
\cline { 3 - 4 } SP600125 & PD98059 & FGF-2 & \\
- & - & - & $23 \pm 3$ \\
- & - & + & $518 \pm 45$ \\
- & + & - & $23 \pm 3$ \\
- & + & + & $326 \pm 31^{*}$ \\
+ & - & - & $21 \pm 2$ \\
+ & - & + & $277 \pm 26^{*}$ \\
+ & + & - & $28 \pm 5$ \\
+ & + & + & $128 \pm 18^{* *}$ \\
& & &
\end{tabular}

${ }^{*} P<0.05$ compared with the value of FGF- 2 alone, ${ }^{*} P<0 \cdot 05$ compared with the value of PD98059 and FGF-2.

transduce the diverse messages (Widmann et al. 1999). In the present study, we demonstrated that FGF-2 induces the phosphorylation of SAPK/JNK in osteoblast-like MC3T3-E1 cells. We have previously shown that FGF-2 activates both p44/p42 MAP kinase and p38 MAP kinase in MC3T3-E1 cells (Tokuda et al. 2000). It is well recognized that MAP kinases are activated by phosphorylation of threonine and tyrosine residues by dual specificity MAP kinase kinase (Raingeaud et al. 1995, Widmann et al. 1999). Therefore, these results strongly suggest that FGF-2 independently activates SAPK/JNK in addition to $\mathrm{p} 44 / \mathrm{p} 42$ MAP kinase and p38 MAP kinase in MC3T3-E1 cells. Furthermore, $2 \mathrm{ng} / \mathrm{ml} \mathrm{FGF-2} \mathrm{in}$ addition to $30 \mathrm{ng} / \mathrm{ml} \mathrm{FGF-2} \mathrm{was} \mathrm{able} \mathrm{to} \mathrm{induce} \mathrm{the}$ phosphorylation of SAPK/JNK in these cells. It has been shown that the $\mathrm{ED}_{50}$ of FGF-2 on most mesodermderived cell types is $60 \mathrm{pg} / \mathrm{ml}$ (Esch et al. 1985). Thus, it is probable that FGF-2 truly activates SAPK/JNK under physiological conditions. As far as we know this is the first report showing FGF-2-induced SAPK/JNK activation in osteoblasts.

Herein, we showed that SP600125, a specific inhibitor of SAPK/JNK (Bennett et al. 2001), significantly suppressed the FGF-2-induced VEGF release in osteoblastlike MC3T3-E1 cells. In addition, we found that SP600125 truly attenuated the phosphorylation of SAPK/ JNK induced by FGF-2 in these cells. We have previously reported that activation of $\mathrm{p} 44 / \mathrm{p} 42$ MAP kinase acts as a positive regulator in the FGF-2-induced VEGF release in MC3T3-E1 cells (Tokuda et al. 2000). However, SP600125 did not affect the FGF-2-induced phosphorylation of $\mathrm{p} 44 / \mathrm{p} 42$ MAP kinase. Thus, it is probable that the SP600125-induced suppression of FGF-2-stimulated VEGF release is due to the inhibition of SAPK/JNK activation. These results strongly suggest that the activation of JNK is involved in FGF-2-stimulated VEGF synthesis in osteoblast-like MC3T3-E1 cells. In addition, we showed that PD98059, a specific inhibitor of mitogenactivated protein kinase (Alessi et al. 1995), had little effect on the phosphorylation of FGF-2-induced SAPK/JNK phosphorylation. Moreover, the FGF-2-stimulated VEGF release was suppressed additively by a combination of SP600125 and PD98059. Therefore, it seems that SAPK/ JNK participates, at least partly, in the FGF-2-stimulated VEGF release independently of p44/p42 MAP kinase. Based on these findings, it is most likely that the VEGF release stimulated by FGF-2 is mediated through the activation of both $\mathrm{p} 44 / \mathrm{p} 42$ MAP kinase and SAPK/JNK in osteoblast-like MC3T3-E1 cells.

We have shown that the FGF-2-stimulated VEGF release is negatively regulated by FGF-2-activated p38 MAP kinase in osteoblast-like MC3T3-E1 cells (Tokuda et al. 2000). However, SP600125 failed to affect the FGF-2-induced phosphorylation of p38 MAP kinase. Furthermore, SB203580, a specific inhibitor of p38 MAP kinase (Cuenda et al. 1995), had little effect on the phosphorylation of FGF-2-induced SAPK/JNK phosphorylation. Taken together, it is probable that FGF-2activated SAPK/JNK plays a part in VEGF release independently of both p44/p42 MAP kinase and p38 MAP kinase in osteoblast-like MC3T3-E1 cells.

The expansion of the capillary network providing microvasculature is an essential process of bone remodeling (Erlebacher et al. 1995). Since VEGF is a specific mitogen of vascular endothelial cells (Ferrara \& Davis-Smyth 1997), it is probable that VEGF synthesized by osteoblasts acts as an important intercellular mediator between osteoblasts and vascular endothelial cells. Moreover, it has been reported that VEGF is involved in trabecular bone formation and expansion of the hypertropic chondrocyte zone in epiphyseal growth plate of the mouse (Gerber et al. 1999), supporting the importance of VEGF in bone metabolism. On the other hand, it is well recognized that FGF-2 is produced and secreted by osteoblasts, and is accumulated in the extracellular matrix of bone (Baylink et al. 1993, Hurley et al. 1993). During bone resorption, it is speculated that FGF-2 in extracellular bone matrix is released and affects osteoblasts existing in the neighborhood. Therefore, it is most likely that FGF-2-induced VEGF synthesis by osteoblasts plays a pivotal role in the process of bone remodeling through regulating the capillary endothelial cells proliferation.

In conclusion, our present results strongly suggest that FGF-2 activates SAPK/JNK in addition to p44/p42 MAP kinase and p38 MAP kinase in osteoblasts, and that $\mathrm{SAPK} / \mathrm{JNK}$ acts as a positive regulator, at least partly, in FGF-2-induced VEGF release.

\section{Acknowledgements}

This investigation was supported, in part, by a Grantin-Aid for Scientific Research from the Ministry of 
Education, Science, Sports and Culture of Japan. We are grateful to Y Okamoto for skilful secretarial assistance.

\section{References}

Alessi DR, Cuenda A, Cohen P, Dudley DT \& Saltiel AR 1995 PD98059 is a specific inhibitor of the activation of mitogenactivated protein kinase in vitro and in vivo. Journal of Biological Chemistry $27027489-27494$.

Baylink DJ, Finkleman RD \& Mohan S 1993 Growth factor to stimulate bone formation. Journal of Bone and Mineral Research $\mathbf{8}$ (Suppl 2) S565-S572.

Bennett BL, Sasaki DT, Murray BW, O’Leary EC, Sakata ST, Xu W, Leisten JC, Motiwala A, Pierce S, Satoh Y, Bhagwat SS, Manning AM \& Anderson DW 2001 SP600125, an anthrapyrazolone inhibitor of Jun N-terminal kinase. PNAS 98 13681-13686.

Bolander ME 1992 Regulation of fracture repair by growth factors stimulate tyrosine kinase activity in vivo. Proceedings of the Society for Experimental Biology and Medicine 200 165-170.

Cuenda A, Rouse J, Doza YN, Meier R, Cohen P, Gallagher TF, Young PR \& Lee JC 1995 SB203580 is a specific inhibitor of a MAP kinase homologue which is stimulated by cellular stresses and interleukin-1. FEBS Letters 364 229-233.

Erlebacher A, Filvaroff EH, Girelman SE \& Derynck R 1995 Toward a molecular understanding of skeletal development. Cell $\mathbf{8 0}$ 371-378.

Esch F, Baird A, Ling N, Ueno N, Hill F, Denoroy L, Klepper R, Gospodarowicz D, Bohlen P \& Guillemin R 1985 Primary structure of bovine pituitary basic fibroblast growth factor (FGF) and comparison with the amino-terminal sequence of bovine brain acidic FGF. PNAS 82 6507-6511.

Ferrara N \& Davis-Smyth T 1997 The biology of vascular endothelial growth factor. Endocrine Reviews 18 4-25.

Gerber H-P, Vu TH, Ryan AM, Kowalski J, Werb Z \& Ferrara N 1999 VEGF couples hypertrophic cartilage remodeling, ossification and angiogenesis during endochondral bone formation. Nature Medicine 5 623-628.

Goad DL, Rubin J, Wang H, Tashijian AH Jr \& Patterson C 1996 Enhanced expression of vascular endothelial growth factor in human SaOS-2 osteoblast-like cells and murine osteoblasts induced by insulin-like growth factor I. Endocrinology 137 2262-2268.

Hurley MM, Abreu C, Harrison JR, Lichtler AC, Raisz LG \& Kream BE 1993 Basic fibroblast growth factor inhibits type I collagen gene expression in osteoblastic MC3T3-E1 cells. Journal of Biological Chemistry 268 5588-5593.

Johnson DE \& Williams LT 1993 Structural and functional diversity in the FGF receptor multigene family. Advances in Cancer Research $\mathbf{6 0}$ $1-41$.

Kato K, Ito H, Hasegawa K, Inaguma Y, Kozawa O \& Asano T 1996 Modulation of the stress-induced synthesis of hsp27 and $\alpha \mathrm{B}$-crystallin by cyclic AMP in C6 glioma cells. Journal of Neurochemistry 66 946-950.
Kozawa O, Tokuda H, Miwa M, Kotoyori J \& Oiso Y 1992 Crosstalk regulation between cyclic AMP production and phosphoinositide hydrolysis induced by prostaglandin $\mathrm{E}_{2}$ in osteoblast-like cells. Experimental Cell Research 198 130-134.

Laemmli UK 1970 Cleavage of structural proteins during the assembly of the head of bacteriophage T4. Nature 227 680-685.

Liu JF, Chevet E, Kebache S, Lemaitre G, Barritault D, Larose L \& Crepin M 1999 Functional Rac-1 and Nck signaling networks are required for FGF-2-induced DNA synthesis in MCF-7 cells. Oncogene 18 6425-6433.

Nijweide PJ, Burger EH \& Feyen JHM 1986 Cells of bone: proliferation, differentiation, and humoral regulation. Physiological Reviews 66 855-886.

Raingeaud J, Gupta S, Rogers JS, Dickens M, Han J, Ulevitch RJ \& David RJ 1995 Pro-inflammatory cytokines and environmental stress cause p38 MAP kinase activation by dual phosphorylation on tyrosine and threonine. Journal of Biological Chemistry $\mathbf{2 7 0}$ 7420-7426.

Schalaeppi JM, Gutzwiller S, Finlenzeller G \& Fournier B 1997 1,25-Dihydroxyvitamin $\mathrm{D}_{3}$ induces the expression of vascular endothelial growth factor in osteoblastic cells. Endocrine Research $\mathbf{2 3}$ 213-229.

Sheikh F, Sontag DP, Fandrich RR, Kardami E \& Cattini PA 2001 Overexpression of FGF-2 increases cardiac myocyte viability after injury in isolated mouse hearts. American Journal of Physiology $\mathbf{2 8 0}$ H1039-H1050.

Sudo H, Kodama H, Amagai Y, Yamamoto S \& Kasai S 1983 In vivo differentiation and calcification in a new clonal osteogenic cell line derived from newborn mouse calvaria. Journal of Cell Biology 96 191-198.

Suzuki A, Shinoda J, Kanda S, Oiso Y \& Kozawa O 1996 Basic fibroblast growth factor stimulates phosphatidylcholine-hydrolyzing phospholipase D in osteoblast-like cells. Journal of Cellular Biochemistry 63 491-499.

Tokuda H, Kozawa O \& Uematsu K 2000 Basic fibroblast growth factor stimulates vascular endothelial growth factor release in osteoblasts: divergent regulation by $\mathrm{p} 44 / \mathrm{p} 42$ mitogen-activated protein kinase and p38 mitogen-activated protein kinase. Journal of Bone and Mineral Research 15 2371-2379.

Wang DS, Yamazaki K, Nohtomi K, Shizume K, Ohsumi K, Shibuya M, Demura H \& Sato K 1996 Increase of vascular endothelial growth factor mRNA expression by 1,25-dihydroxyvitamin $\mathrm{D}_{3}$ in human osteoblast-like cells. Journal of Bone and Mineral Research 11 472-479.

Widmann C, Gibson S, Jarpe MB \& Johnson GL 1999 Mitogen-activated protein kinase: conservation of a three-kinase module from yeast to human. Physiological Reviews 79 143-180.

Received 30 September 2002

Accepted 15 January 2003 